\title{
Surgical treatment of solitary adrenal metastasis from non- small cell lung cancer
}

\author{
Olaf Mercier, MD, Elie Fadel, MD, PhD, Marc de Perrot, MD, Sacha Mussot, MD, Franco Stella, MD, \\ Alain Chapelier, MD, PhD, and Philippe Dartevelle, MD
}

From the Department of Thoracic and Vascular Surgery and Heart-Lung Transplantation, Marie Lannelongue Hospital, Le Plessis Robinson, France.

Received for publication June 9, 2004; revisions received Sept 3, 2004; accepted for publication Sept 22, 2004.

Address for reprints: Elie Fadel, MD, PhD, Department of Thoracic and Vascular Surgery and Heart-Lung Transplantation, Marie Lannelongue Hospital, 133 Avenue de la Résistance, 92350 Le Plessis Robinson, France (E-mail: fadel@ccml.com).

J Thorac Cardiovasc Surg 2005;130:136-40 $0022-5223 / \$ 30.00$

Copyright (C) 2005 by The American Association for Thoracic Surgery

doi:10.1016/j.jtcvs.2004.09.020
Background: Management of solitary adrenal metastasis from non-small cell lung cancer is still debated. Although classically considered incurable, various reports with small numbers of patients have shown that surgical treatment might improve long-term survival. The aim of this study was to review our experience and to identify factors that could affect survival.

Methods: From January 1989 through April 2003, 23 patients underwent complete resection of an isolated adrenal metastasis after surgical treatment of non-small cell lung cancer. There were 19 men and 4 women, with a mean age of $54 \pm 10$ years. The diagnosis of adrenal metastasis was synchronous with the diagnosis of nonsmall cell lung cancer in 6 patients and metachronous in 17 patients. The median disease-free interval for patients with metachronous metastasis was 12.5 months (range, 4.5-60.1 months).

Results: The overall 5-year survival was $23.3 \%$. Univariate and multivariate analysis demonstrated that a disease-free interval of greater than 6 months was an independent and significant predictor of increased survival in patients after adrenalectomy. All patients with a disease-free interval of less than 6 months died within 2 years of the operation. The 5-year survival was $38 \%$ after resection of an isolated adrenal metastasis that occurred more than 6 months after lung resection. Adjuvant therapy and pathologic staging of non-small cell lung cancer did not affect survival.

Conclusions: Surgical resection of metachronous isolated adrenal metastasis with a disease-free interval of greater than 6 months can provide long-term survival in patients previously undergoing complete resection of the primary non-small cell lung cancer.

1 drenal glands are a common metastatic site for non-small cell lung cancer (NSCLC). Metastases are the sign of a general spread of disease and usually occur as multiple metastases. Solitary adrenal metastasis from NSCLC is a rare event. The incidence was evaluated in 2 prospective studies to be only $1.6 \%{ }^{1}$ and $3.5 \%$ of resectable NSCLC. Nonsurgical treatment of a solitary adrenal metastasis is associated with poor survival. Over the last 10 years, several observations and short case series have observed that long-term survival after adrenalectomy was possible..$^{2-7}$ Multicenter reports suggested that surgical treatment of solitary adrenal metastasis from resectable NSCLC could potentially improve survival. ${ }^{8}$ We report our experience with surgical treatment of solitary adrenal metastasis from resectable NSCLC. The aim of this study was to evaluate the result of surgical treatment on survival and to establish the variables that could influence survival to select patients who could expect a benefit from adrenalectomy.

\section{Patients and Methods}

Between January 1989 and April 2003, 33 of 3125 patients undergoing lung cancer resections in our department were found to have an isolated adrenal mass. After an 
TABLE 1. Characteristics of patients who underwent lung and adrenal gland resection for synchronous and metachronous metastases

\begin{tabular}{|c|c|c|c|c|c|c|c|}
\hline Patient no. & $\begin{array}{l}\text { Primary lung } \\
\text { cancer } \\
\text { classification }\end{array}$ & $\begin{array}{c}\text { Primary lung } \\
\text { cancer } \\
\text { histologic type }\end{array}$ & DFI (mo) & $\begin{array}{l}\text { Adjuvant therapy } \\
\text { after } \\
\text { adrenalectomy }\end{array}$ & Status & Recurrences & $\begin{array}{c}\text { Survival after } \\
\text { adrenalectomy } \\
(\mathrm{mo})\end{array}$ \\
\hline 1 & T2 N1 Mo & LCC & 5 & None & Dead & Yes & 7 \\
\hline 2 & T2 N1 Mo & SCC & 10 & None & Dead & Yes & 41 \\
\hline 3 & T2 N1 Mo & ADK & 7 & None & Dead & No & 100 \\
\hline 4 & T3 NO MO & SCC & 13 & None & Dead & Yes & 16 \\
\hline 5 & T2 N2 Mo & ADK & 24 & Chemo & Alive & No & 110 \\
\hline 6 & T2 N1 Mo & SCC & 8 & $\mathrm{Rx}$ & Alive & Yes & 94 \\
\hline 7 & T3 N1 Mo & ADK & 9 & $\mathrm{Rx}$ & Dead & Yes & 6 \\
\hline 8 & T2 N1 Mo & SCC/ADK & 6 & None & Dead & Yes & 11 \\
\hline 9 & T2 N1 Mo & SCC & 24 & None & Dead & Yes & 2 \\
\hline 10 & T3 N1 M1 & ADK & 0 & Rx/Chemo & Dead & Yes & 16 \\
\hline 11 & T4 N2 M0 & SCC & 6 & None & Dead & Yes & 5 \\
\hline 12 & T2 No M1 & SCC & 0 & None & Dead & Yes & 2 \\
\hline 13 & T2 No Mo & SCC & 20 & Rx/Chemo & Dead & No & 9 \\
\hline 14 & T3 NO MO & LCC & 14 & None & Alive & No & 30 \\
\hline 15 & T2 N1 M1 & ADK & 0 & $\mathrm{Rx}$ & Dead & No & 8 \\
\hline 16 & T2 N1 M0 & SCC & 18 & None & Dead & Yes & 34 \\
\hline 17 & T1 No Mo & ADK & 15 & $\mathrm{Rx} /$ Chemo & Alive & Yes & 41 \\
\hline 18 & T3 N2 M0 & SCC & 6 & Rx/Chemo & Dead & Yes & 16 \\
\hline 19 & T2 N1 M1 & ADK & 0 & None & Dead & No & 10 \\
\hline 20 & T2 N2 M0 & ADK & 14 & Rx/Chemo & Dead & Yes & 13 \\
\hline 21 & T3 NO MO & ADK & 60 & $\mathrm{Rx} /$ Chemo & Alive & No & 14 \\
\hline 22 & T3 No M1 & ADK & 0 & Chemo & Alive & No & 9 \\
\hline 23 & T4 N1 M1 & SCC & 0 & None & Alive & No & 0.3 \\
\hline
\end{tabular}

$D F I$, Disease-free interval; $L C C$, large cell carcinoma; $S C C$, squamous cell carcinoma; $A D K$, adenocarcinoma; Chemo, chemotherapy; $R x$, radiotherapy.

extensive workup to exclude metastasis to other sites, all adrenal masses that were compatible with an isolated adrenal metastasis were completely resected. A total of 23 patients were given a diagnosis of an isolated adrenal metastasis from NSCLC, and these patients form the basis of the present study. Ten patients presented with an adenoma of the adrenal gland that was unrelated to the diagnosis of NSCLC.

There were 19 men and 4 women, with a mean age of $54 \pm$ 10 years (range, 35-70 years). All patients underwent spiral computed tomography (CT) scanning of the thorax and upper abdomen, as well as cerebral CT scanning, as part of the staging for NSCLC. Bone scanning was performed in symptomatic patients or in patients with abnormal alkaline phosphatase levels. Mediastinoscopy was performed when thoracic CT scanning detected mediastinal lymph nodes with a short-axis diameter of $1 \mathrm{~cm}$ or more. Patients with involvement of mediastinal lymph nodes proved histologically underwent induction chemotherapy before the operation. In all patients complete resection of the primary lung cancer was performed before the adrenalectomy (Table 1). Mediastinal lymphadenectomy or lymph node sampling was performed in all patients.

\section{Diagnosis of Isolated Adrenal Metastasis}

All patients were asymptomatic at the time of presentation. Six patients presented with an isolated adrenal metastasis discovered during the preoperative workup of the primary lung tumor (syn- chronous metastasis). The remaining 17 patients presented with a metastasis that was discovered during follow-up after the primary lung tumor was resected surgically (metachronous metastasis). In 10 patients the metastasis was detected on routine follow-up chest CT scanning, and in 7 patients an increased serum carcinoembryonic antigen (CEA) level prompted a metastatic search by means of CT scanning.

We defined a disease-free interval (DFI) corresponding to the time interval between the surgical treatment of the primary tumor and the diagnosis of the adrenal metastasis. For synchronous metastasis, this interval was nil. Survival was calculated from the date of adrenalectomy to death or the date of last follow-up. Disease-free survival is defined as the time interval from the adrenalectomy to the date of last follow-up or the date of disease recurrence. Complete follow-up was available for all patients.

\section{Treatment of Isolated Adrenal Metastasis}

Complete unilateral adrenalectomy was performed by means of either a transperitoneal approach $(\mathrm{n}=14)$ or an extraperitoneal approach $(n=9)$, depending on the tumor's size. Small tumors without local invasion were removed through a right or left upper quadrant laparotomy. Adjacent organs, such as the kidney $(\mathrm{n}=2)$, inferior vena cava $(n=1)$, or the liver $(n=1)$, were partially resected en bloc with the tumor in 4 patients. Routine frozen sections were obtained to ensure excision of the tumor with tumor- 


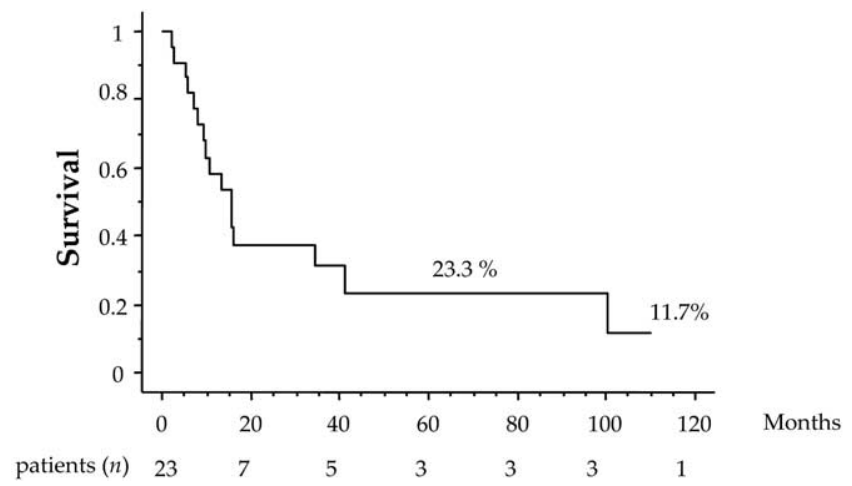

Figure 1. Overall survival of the 23 patients after resection of solitary adrenal metastasis from resected NSCLC calculated with the Kaplan-Meier method.

free margins. Regional lymphadenectomy was not routinely performed. Decisions for complementary treatment, such as localized radiation therapy or chemotherapy, were made on a case-by-case basis after discussion with the medical oncologist. No particular criteria were defined for adjuvant treatment.

\section{Statistical Analysis}

All results are expressed as means \pm SE. Survivals were calculated by means of life-table analysis. Kaplan-Meier curves were plotted and compared by using the log-rank test for univariate analysis. Variables tested were sex, serum CEA level, DFI, metachronous or synchronous metastasis, $\mathrm{T}$ and $\mathrm{N}$ status of the primary lung cancer, histology of the primary lung cancer, adjuvant chemotherapy, adjuvant radiotherapy of the adrenal bed, metastasis location (homolateral or contralateral), size of adrenal metastasis, and invasion of the adrenal capsule. Multivariate analysis of independent prognostic factors was assessed by using the Cox proportional hazards stepwise model with Statview V (Abacus Concept, Berkeley, Calif).

\section{Results}

\section{Primary Lung Cancer}

Histologic findings and stages of the primary lung cancer are presented in Table 1. Neoadjuvant platinum-based chemotherapy was administered to 2 patients who had histologically proved $\mathrm{N} 2$ disease and 1 patient with synchronous adrenal metastasis. All other patients have been initially treated with complete surgical resection of the primary tumor. Adjuvant platinum-based chemotherapy and radiation therapy of the mediastinum (mean, $50 \mathrm{~Gy}$ ) was given to patients with postoperatively proved N2 disease $(n=4)$ or with locally advanced tumor ( $\mathrm{T} 3$ or $\mathrm{T} 4, \mathrm{n}=7$ ). Three patients with synchronous adrenal metastasis also received adjuvant platinum-based chemotherapy and radiation therapy of the adrenal bed.

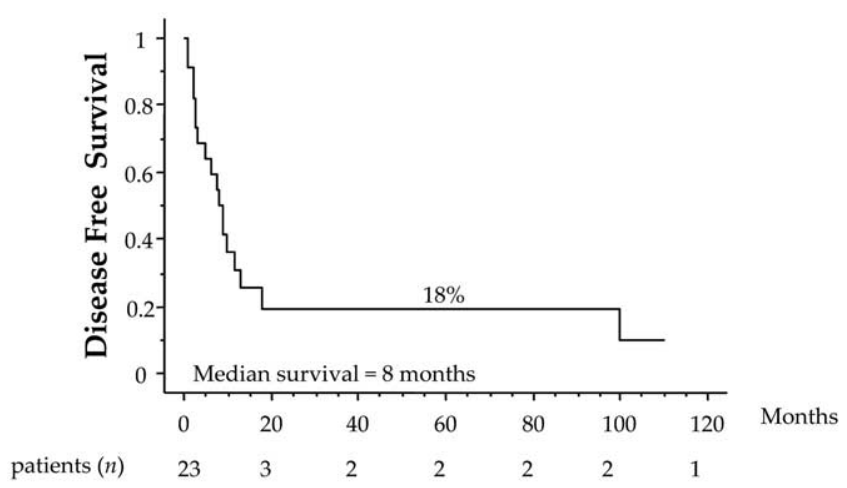

Figure 2. Kaplan-Meier disease-free survival curve of the 23 patients after resection of solitary adrenal metastasis from resected NSCLC.

\section{Adrenal Metastasis}

The median size of the adrenal metastasis was $5.8 \mathrm{~cm}$ (range, 2-11 cm). The median DFI for patients with metachronous metastasis was 12.5 months (range, 4.5-60.1 months). Synchronous metastases of the adrenal gland were resected a mean of 2 months (range, 0.5-4 months) after lung resection in 5 patients and during the same operative procedure in 1 patient. There were no perioperative deaths. However, 3 (13\%) patients experienced postoperative complications: one bronchopleural fistula successfully treated with thoracoplasty and antibiotics, one covered evisceration on the ninth postoperative day treated surgically, and one cardiac arrhythmia treated medically.

Histologic findings confirmed the diagnosis of NSCLC metastasis. Surgical margins were free of disease in all patients. However, tumor invaded the adrenal capsule in 15 $(65 \%)$ patients. Twelve $(52 \%)$ patients underwent adjuvant therapy: 3 cycles of platinum-based chemotherapy alone $(\mathrm{n}=3)$, radiation therapy (mean, $45 \mathrm{~Gy})$ to the adrenal bed alone $(\mathrm{n}=3)$, and a combination of radiation and chemotherapy $(\mathrm{n}=6)$.

The mean follow-up period after adrenalectomy was 26 months (range, 0.3-110 months). During follow-up, 14 $(61 \%)$ patients had recurrence of NSCLC. Recurrence was local (in the operated adrenal bed) in 4 patients, local and systemic in 1 patient, and systemic in 9 patients. Systemic recurrence was limited to only one distant organ in 5 patients, the brain $(\mathrm{n}=3)$, the contralateral adrenal gland $(\mathrm{n}=$ $1)$, and the contralateral lung $(\mathrm{n}=1)$, and was spread to multiple organs in the other 5 patients.

All patients presenting with local recurrences had capsular invasion of the adrenal gland on histologic examination. Local recurrence was not significantly different between patients undergoing adjuvant therapy or not. Local recurrences were treated with radiation therapy (mean, 60 Gy) in 3 patients and with an extended surgical resection 
TABLE 2. Predictor factors of worse survival

\begin{tabular}{lcc}
\hline \multicolumn{1}{c}{ Predictor factors } & $\begin{array}{c}\text { Univariate } \\
\text { analysis } \boldsymbol{P} \\
\text { value }\end{array}$ & $\begin{array}{c}\text { Multivariate } \\
\text { analysis } \boldsymbol{P} \\
\text { value }\end{array}$ \\
\hline $\mathrm{T}$ & .74 & - \\
$\mathrm{N}$ & .71 & - \\
Adrenal capsule invasion & .71 & - \\
Size of adrenal metastasis & .41 & - \\
Adenocarcinoma or not & .43 & - \\
Adjuvant therapy & .28 & - \\
Serum CEA level & .27 & - \\
Homolateral-contralateral & .89 & - \\
Synchronous-metachronous & .1 & - \\
DFI $<6$ mo & .005 & .01 \\
\hline
\end{tabular}

$C E A$, Carcinoembryonic antigen; $D F I$, disease-free interval.

(enlarged nephrectomy) in the remaining patient. This patient is currently alive and free of disease 88 months later.

After a median survival of 13.3 months, the 2- and 5-year survivals were $37 \%$ and $23.3 \%$, respectively (Figure 1). The overall median disease-free survival was 8 months, and the 5 -year disease free survival was $18 \%$ (Figure 2). TNM status, histology of the lung cancer, adjuvant therapy, preoperative serum CEA level, metastasis location (homolateral or contralateral) and size, and capsular invasion of the adrenal gland did not influence survival. Univariate and multivariate analysis demonstrated that a DFI of greater than 6 months was the only significant and independent predictor of increased survival in patients after adrenalectomy (Table 2). All patients with a DFI of less than 6 months died within 2 years after resection of the adrenal gland, whereas $38 \%$ of the patients with a DFI of greater than 6 months were alive at 5 years after adrenalectomy (Figure 3).

\section{Discussion}

Although management of isolated adrenal metastases from NSCLC is still debated, this study demonstrates that surgical resection can provide long-term survival without operative death or major complications. The 5-year survival reached $38 \%$ after resection of an isolated metachronous adrenal metastasis occurring more than 6 months after resection of the primary lung cancer, whereas all patients with synchronous metastasis or with a DFI of less than 6 months died within 2 years after the adrenalectomy. A DFI of greater than 6 months was the only independent predictor of increased survival. Other factors, such as the $\mathrm{T}$ and $\mathrm{N}$ staging of the primary tumor, histology, administration of adjuvant therapy, or size of the metastasis, had no effect on survival.

During the last 2 decades, several case reports and small series showed long-term survival after surgical resection of isolated adrenal metastasis if complete resection of both the primary tumor and the metastasis could be achieved (Table

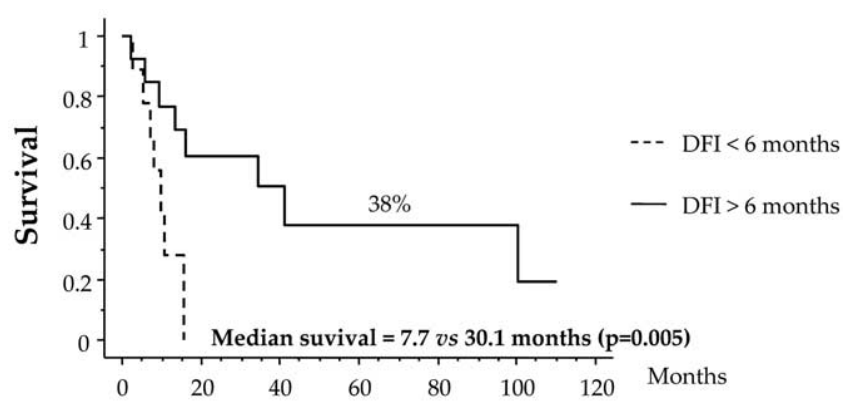

Figure 3. Kaplan-Meier survival curves according to DFI.

3). ${ }^{6,8-12}$ Hence our policy over the past 15 years in patients with resectable NSCLC has been to remove all adrenal masses that were compatible with an isolated adrenal metastasis after an extensive workup was performed. Fluorodeoxyglucose positron emission tomography was used to rule out metastasis to other locations than the adrenal gland during the last 4 years of the study. Interestingly, despite positive fixation on preoperative positron emission tomography scanning in 4 patients, one was found to have a benign adenoma on postoperative histology.

In agreement with previous studies, ${ }^{2,4-10,13-16}$ our results confirmed that resection of adrenal metastasis can improve survival in patients with complete resection of their NSCLC. We observed 3 patients alive more than 5 years after the adrenalectomy and found a 5-year survival of $23.3 \%$ (Figure 1). These results are similar to the survivals of patients undergoing isolated brain metastasis resection. ${ }^{17-20}$ Surgical treatment of solitary brain metastasis from NSCLC has been shown to improve survival compared with radiotherapy ${ }^{17}$ and to be associated with 5-year survivals ranging between $13 \%$ and $30 \% .^{18-20}$

We could also corroborate our results to those from Higashiyama and colleagues ${ }^{11}$ and Kim and associates, ${ }^{21}$ who found that a DFI of less than 6 months and synchronous metastasis were associated with worse survivals. This finding suggests that a DFI of less than 6 months is an indicator of either tumor aggressiveness or advanced tumor stage that remained undetected at the time of resection of the primary tumor. We observed that no patients with synchronous metastasis or with a DFI of less than 6 months survived more than 2 years after the operation in our series. Induction therapy could potentially improve survival in this group of patients. Luketich and Burt ${ }^{14}$ reported a much better median survival (31 months) than we did in patients with synchronous metastases after neoadjuvant chemotherapy and adrenal resection. Further studies are required to confirm this finding.

\section{Conclusion}

In conclusion, long-term survival after resection of isolated NSCLC metastasis to the adrenal gland is possible. A DFI of 
TABLE 3. Surgical and nonsurgical treatment of isolated adrenal metastases from NSCLC

\begin{tabular}{|c|c|c|c|c|c|}
\hline Author & $\mathbf{n}$ & $\mathbf{M} / \mathbf{S}$ & $\begin{array}{c}\text { Median } \\
\text { survival (mo) }\end{array}$ & Survival (\%) & Long-term survivors \\
\hline \multicolumn{6}{|l|}{ Nonsurgical treatment } \\
\hline Soffen et al ${ }^{12}$ & 9 & & 6 & & None \\
\hline Luketich and Burt ${ }^{10}$ & 6 & $0 / 6$ & 8.5 & & All dead at $21 \mathrm{mo}$ \\
\hline Higashiyama et al ${ }^{11}$ & 4 & $2 / 2$ & $<6$ & & None \\
\hline \multicolumn{6}{|l|}{ Surgical treatment } \\
\hline Luketich and Burt ${ }^{10}$ & 8 & $0 / 8$ & 31 & & One patient alive at $61 \mathrm{mo}$ \\
\hline Higashiyama et al ${ }^{11}$ & 5 & $4 / 1$ & $>9$ & & One patient was disease free at $40 \mathrm{mo}$ \\
\hline Twomey et $\mathrm{al}^{6}$ & 2 & $1 / 1$ & & & $\begin{array}{l}\text { One patient was alive at } 14 \mathrm{y} \text { and the } \\
\text { other at } 5 \mathrm{y}\end{array}$ \\
\hline Porte et al ${ }^{8}$ & 43 & $21 / 22$ & 11 & $11 \%$ at $4 y$ & Two patients alive at $90 \mathrm{mo}$ \\
\hline Bretcha-Boix et al ${ }^{9}$ & 5 & $2 / 3$ & 21 & & Two patients alive at $50 \mathrm{mo}$ \\
\hline Marie Lannelongue & 23 & $17 / 6$ & 13.3 & $23.3 \%$ at $5 y$ & Three patients alive at 94,100 , and 110 mo \\
\hline
\end{tabular}

$M$, Metachronous; $S$, synchronous.

more than 6 months appears to be the only factor that influences survival. Hence, surgical resection of metachronous isolated adrenal metastasis should be the treatment of choice if the DFI is greater than 6 months and complete resection of the primary NSCLC is achieved.

\section{References}

1. Ettinghausen SE, Burt ME. Prospective evaluation of unilateral adrenal masses in patient with operable non-small cell lung cancer. J Clin Oncol. 1991;9:462-6.

2. Porte H, Roumilhac D, Graziana JP, et al. Adrenalectomy for a solitary adrenal metastasis from lung cancer. Ann Thorac Surg. 1998;65:331-5.

3. Lam KY, Lo CY. Metastatic tumours of the adrenal glands: a 30-year experience in a teaching hospital. Clin Endocrinol (Oxf). 2002;56:95101.

4. Reyes L, Parvez Z, Nemoto T, Regal AM, Takita H. Adrenalectomy for adrenal metastases from lung carcinoma. J Surg Oncol. 1990;44: 32-4.

5. Raviv G, Klein E, Yellin A, Schneebaum S, Ben-Ari G. Surgical treatment of solitary adrenal metastases from lung carcinoma. J Surg Oncol. 1990;43:123-4.

6. Twomey P, Montgomery C, Clark O. Successful treatment of adrenal metastases from large-cell carcinoma of the lung. JAMA. 1982;248: 581-3.

7. Luketich JD, Burt ME. Does resection of isolated adrenal metastases in non-small cell lung cancer improve survival? Ann Thorac Surg. 1996;62:1614-6.

8. Porte H, Siat J, Guibert B, et al. Resection of adrenal metastases from non-small cell lung cancer: a multicenter study. Ann Thorac Surg. 2001;71:981-5.

9. Bretcha-Boix P, Rami-Porta R, Mateu-Navarro M, Hoyuela-Alonso C, Marco-Molina C. Surgical treatment of lung cancer with adrenal metastasis. Lung Cancer. 2000;27:101-5.
10. Luketich JD, Burt ME. Does resection of adrenal metastases from NSCLC improve survival? Ann Thorac Surg. 1996;62:1614-6.

11. Higashiyama M, Doi O, Kodama K, Yokouchi H, Imaoka S, Koyama H. Surgical treatment of adrenal metastasis following pulmonary resection for lung cancer: comparison of adrenalectomy with palliative therapy. Int J Surg. 1994;79:124-9.

12. Soffen EM, Solin LJ, Rubenstein JH, Hanks GE. Palliative radiotherapy for symptomatic adrenal metastases. Cancer. 1990;65:1318-20.

13. Lo CY, Van Heerden JA, Soreide JA, et al. Adrenalectomy for metastatic disease to the adrenal glands. Br J Surg. 1996;83:528-33.

14. Ambrogi V, Tonini G, Mineo TC. Prolonged survival after extracranial metastasectomy from synchronous resectable lung cancer. Ann Surg Oncol. 2001;8:663-6.

15. de Perrot M, Licker M, Robert JH, Spiliopoulos A. Long-term survival after surgical resections of bronchogenic carcinoma and adrenal metastasis. Ann Thorac Surg. 1999;68:1084-5.

16. Urschel JD, Finley RK, Takita H. Long-term survival after bilateral adrenalectomy for metastatic lung cancer: a case report. Chest. 1997; 112:848-50.

17. Patchell RA, Tibbs PA, Walsh JW, et al. A randomized trial of surgery in the treatment of single metastases to the brain. $N$ Engl J Med. 1990;322:494-500.

18. Burt M, Wronski M, Arbit E, Galicich JH. Resection of brain metastases from non-small-cell lung carcinoma. Results of therapy. Memorial Sloan-Kettering Cancer Center Thoracic Surgical Staff. $J$ Thorac Cardiovasc Surg. 1992;103:399-410.

19. Macchiarini P, Buonaguidi R, Hardin M, Mussi A, Angeletti CA. Results and prognostic factors of surgery in the management of nonsmall cell lung cancer with solitary brain metastasis. Cancer. 1991; 68:300-4.

20. Read RC, Boop WC, Yoder G, Schaefer R. Management of nonsmall cell lung carcinoma with solitary brain metastasis. J Thorac Cardiovasc Surg. 1989;98:884-90.

21. Kim SH, Brennan MF, Russo P, Burt ME, Coit DG. The role of surgery in the treatment of clinically isolated adrenal metastasis. Cancer. 1998;82:389-5. 